\title{
Optimal load frequency control through combined state and control gain estimation for noisy measurements
}

\author{
Anju G. Pillai ${ }^{1,2^{*}}$ (D) Elizabeth Rita Samuel ${ }^{1,2}$ and A. Unnikrishnan ${ }^{1,2}$
}

\begin{abstract}
Combined estimation of state and feed-back gain for optimal load frequency control is proposed. Load frequency control (LFC) addresses the problem of controlling system frequency in response to disturbance, and is one of main research areas in power system operation. A well acknowledged solution to this problem is feedback stabilization, where the Linear Quadratic Regulator (LQR) based controller computes the feedback gain $\mathrm{K}$ from the known system parameters and implements the control, assuming the availability of all the state variables. However, this approach restricts control to cases where the state variables are readily available and the system parameters are steady. Alternatively, by estimating the states continuously from available measurements of some of the states, it can accommodate dynamic changes in the system parameters. The paper proposes the technique of augmenting the state variables with controller gains. This introduces a non-linearity to the augmented system and thereby the estimation is performed using an Extended Kalman Filter. This results in producing controller gains that are capable of controlling the system in response to changes in load demand, system parameter variation and measurement noise.
\end{abstract}

Keywords: Load frequency control, State feedback control, Linear quadratic regulator, Extended Kalman filter, Single area power system

\section{Introduction}

To control a power system against frequency variation in response to changes in demand, load frequency control (LFC) is a well acknowledged strategy. LFC has been addressed in the literature in great detail [1-7]. By and large, all the investigations extensively utilize optimal control theory to develop LFC. However, the difficulty in recording in real time all the state variables from the system required in the above approaches has been the major concern for the implementation of the techniques [8]. In order to alleviate the problems, the reconstruction of all the states from available outputs and controls using an observer has received significant attention $[8,9]$.

\footnotetext{
* Correspondence: anjugpillai@gmail.com

'Department of Electrical \& Electronics Engineering, Rajagiri School of Engineering \& Technology, Ernakulam, Kerala 682037, India

${ }^{2}$ APJ Abdul Kalam Technological University, Thiruvananthapuram, Kerala, India
}

The design of most observers requires the determination of observer gains, such that the eigenvalues of the characteristic equation on the observation error match a set of pre-assigned values [8]. While the pre-assignment eigenvalues is straightforward for small systems, it along with the states from a limited number of measuretor, is presented to minimize the error between the meaKalman Filter (EKF).

The automatic generation control (AGC) or the LFC problem dates back to 1950's [1, 10]. With the change of power system structure and the growth in size and 
complexity of interconnected systems [11], it has become imperative that the total power generation and load demand match well all the time, and any deviation in the demand of power could change the operating point and reflect the disturbance onto the frequency [12, 13]. Stable system frequency and steady interchange of tie line power with neighboring control areas are the two main attributes required to be guaranteed by LFC $[4,11,14]$. In a typical power system, the number of variables influencing the performance can be quite large.

In [15], an improved LFC method is introduced which has better performance in a multi-area power system including HVDC transmission links. The LQR method is used along with the Kalman Filter because all the system states may not be available, and the measurements may not be free from noise. The Kalman Filter estimates the unmeasurable states and incorporates the optimal gain of LQR for the control of frequency. Reference [16] presents the importance of a classical control method such as integral control in the LFC problem. However, this approach does not provide adequate control performance when uncertainties arise in the system parameters.

Implementation of optimal control theory into the control of power system faces difficulties in the selection of $\mathrm{Q}$ and $\mathrm{R}$ matrices for the design of the LQR controller [9]. Typically, feedback gain $\mathrm{K}$ is computed from the weighting matrices of the LQR controller. To avoid the difficulties in computing $\mathrm{Q}$ and $\mathrm{R}$ matrices for $\mathrm{LQR}$ controller, an estimation technique is proposed in [9] which augments the required feedback gain $\mathrm{K}$, along with the system state estimation through Extended Kalman Filter method.

For multi-area power systems, the complexity increases and there will be a dimensional expansion of the dynamic states. Most states may be unmeasurable, and in such cases, state estimation can be performed with the Kalman estimator from limited measurements. However, for control purposes some optimal methods are preferred. Therefore, the paper proposes a novel technique of augmenting the states with optimal gains for estimation. It also incorporates parameter uncertainties in the system. On augmenting the gains along with states, the state space equation becomes nonlinear and thus Extended Kalman Filter is considered for the estimation in the new augmented system.

Since real time measurements are always noisy, the proposed technique is designed in such a way that it can handle measurement noise variance better than conventional control methods. For the incorporation of noise, no additional tuning is needed for this technique, while the computational time required is also comparatively reduced.

Accordingly, in the sections to follow, control strategy based on state space theory is used to formulate LFC implementation. The basic idea of state estimation using

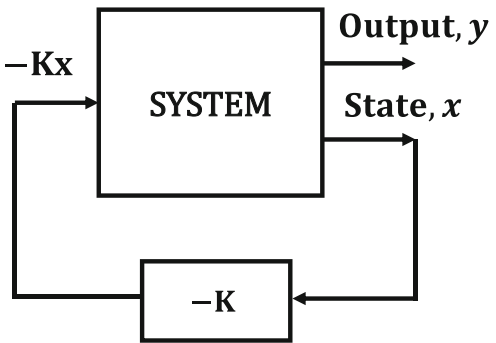

Fig. 1 State space implementation of Load Frequency Control

EKF is introduced in Section 4, followed by the proposed LFC. Detailed simulation results are given in Section 6 . These are summarized for three cases with different noise variances injected to frequency measurements. A comparative study is also provided with LQR [15] and integral control [16]. The system used for verification is discussed in detail in the Appendix.

\section{State feedback control}

The discrete-time state-space model with $\mathrm{p}$ inputs, $\mathrm{q}$ outputs and $\mathrm{n}$ state variables is considered as

$$
\begin{aligned}
& X_{(k+1)}=A X_{(k)}+B u_{(k)} \\
& z_{(k)}=H^{T} X_{(k)}
\end{aligned}
$$

where.

A is the state matrix of dimension $(n \times n)$.

$B$ is the input matrix of dimension $(n \times p)$.

$\mathrm{H}$ is the output matrix of dimension $(\mathrm{q} \times \mathrm{n})$.

$X_{(k)}$ is the state vector of dimension $\mathrm{n}$.

$u_{(k)}$ is the input vector of dimension $\mathrm{p}$.

$z_{(k)}$ is the output vector of dimension $\mathrm{q}$.

Assuming that all the states of the system are measurable, a state feedback control law uses the current states of the plant in order to determine the control effort, $u_{(k)}=g\left(X_{(k)}\right)[17,18]$. Thus, choosing $g\left(X_{(k)}\right)$ to be in the form $g\left(X_{(k)}\right)=-K^{T} X_{(k)}$, where $\mathrm{K}$ is the gain matrix of dimension $(\mathrm{n} \times \mathrm{p})$, the closed-loop system dynamics are given by

$$
\boldsymbol{X}_{(\boldsymbol{k}+1)}=\left(\boldsymbol{A}-\boldsymbol{B} \boldsymbol{K}^{T}\right) \boldsymbol{X}_{(\boldsymbol{k})}
$$

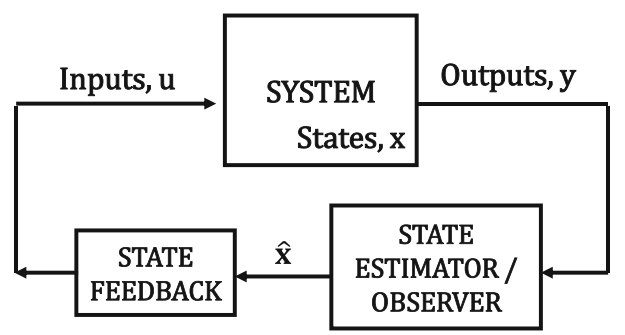

Fig. 2 State feedback control 


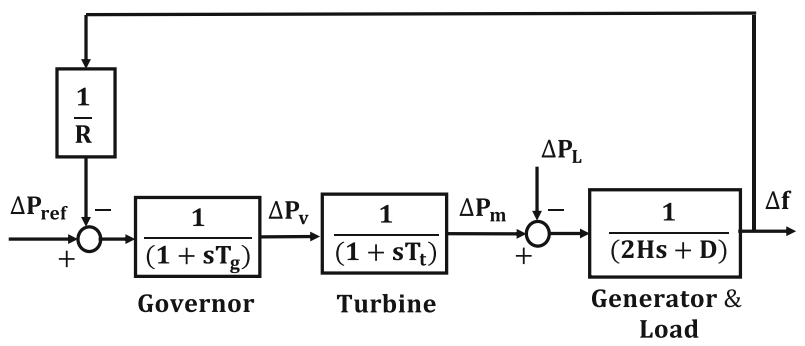

Fig. 3 Single area power system
Figure 1 illustrates the scheme. It may be noted from (3) that $\mathrm{K}$ can be used to place the poles of the closed loop system in order to obtain a desired behavior.

\section{Linear quadratic regulator control}

Assuming that all the state variables are simultaneously measurable, the LQR control strategy forms an optimal method to compute the value of $\mathrm{K}$, where the optimal solution is given by minimizing a linearquadratic cost function [18]. The LQR approach presumes that a gain which stabilizes the system is guaranteed to offer a valid solution for the problem [19]. Hence, for the dynamic system in (1) and (2), the control gain for the LQR controller minimizes the cost function given by [18]

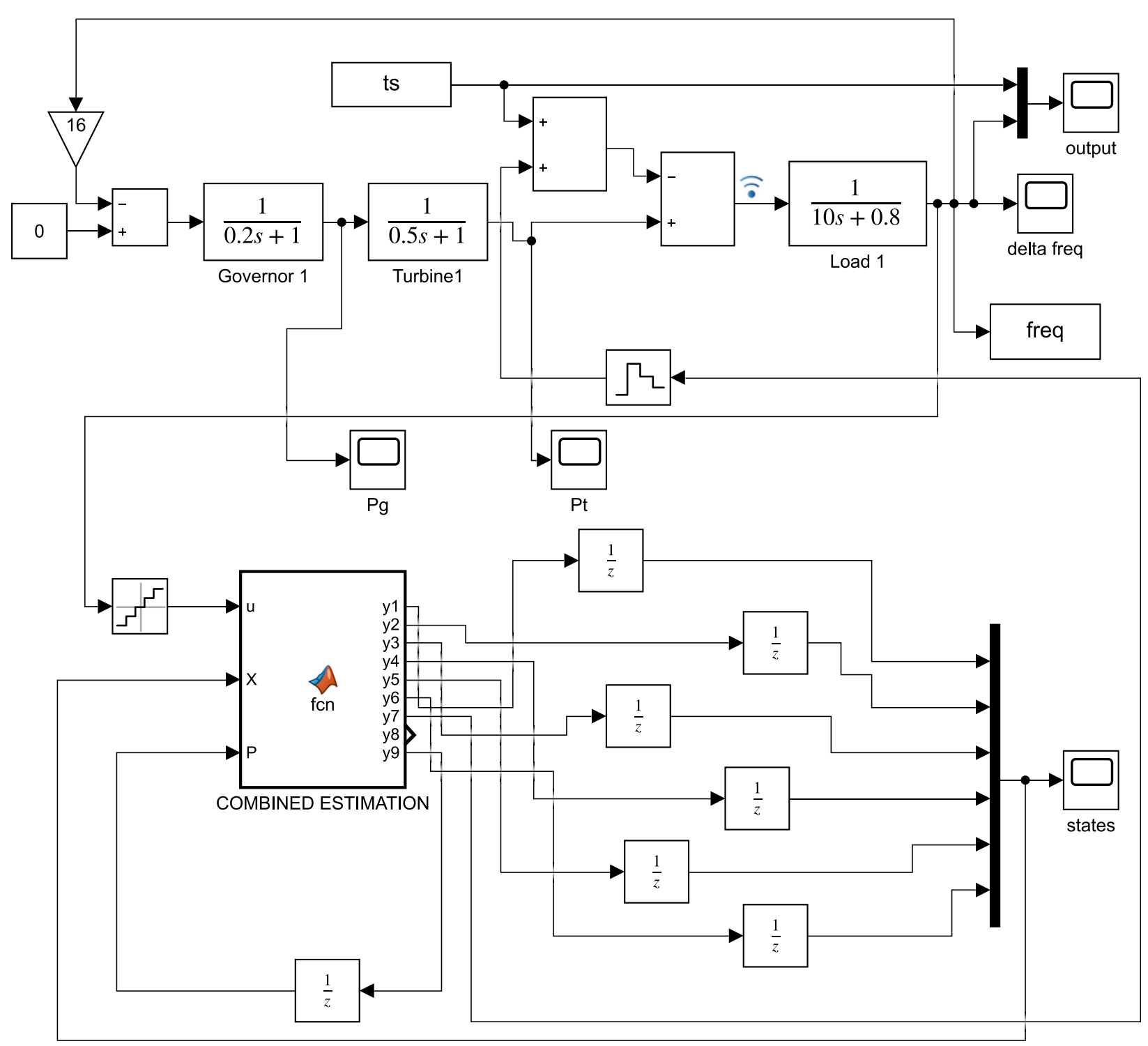

Fig. 4 Implementation of the proposed LFC in MATLAB / Simulink 


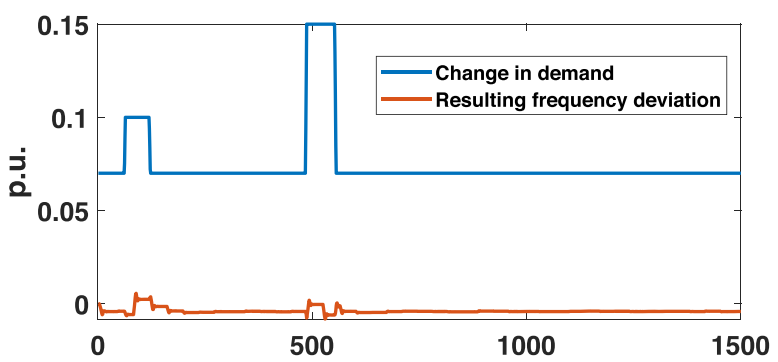

(a)

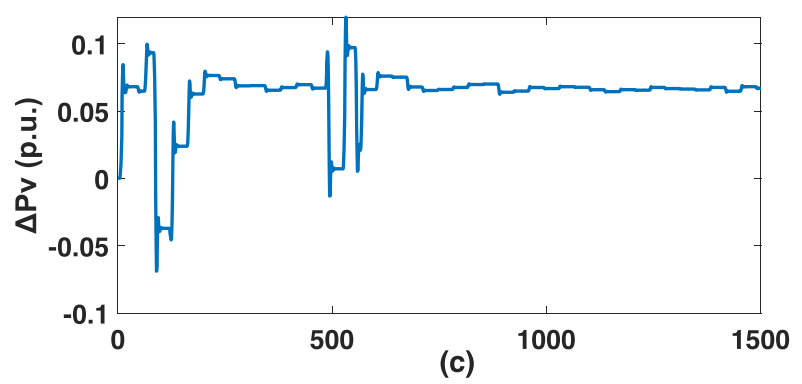

Time (s)

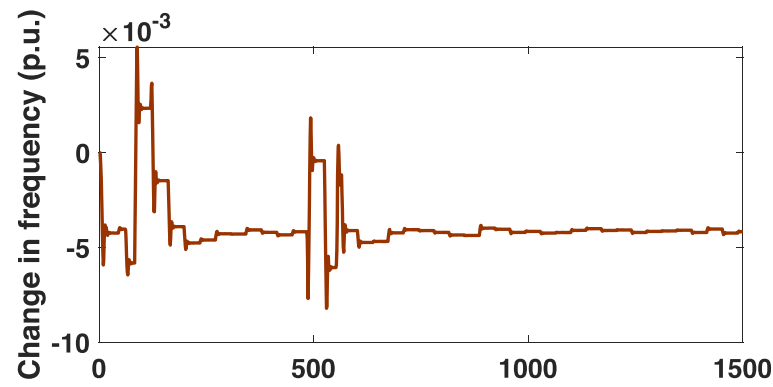

(b)

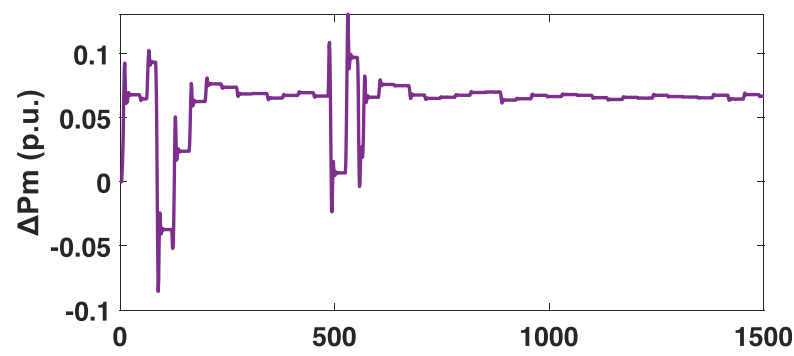

(d)

Fig. 5 System response during changes in demand with frequency measurement noise variance of 0.005: a Variation in $\Delta f$; $\mathbf{b}$ Frequency response during control action; $\boldsymbol{c}$ Variation of states $\Delta \mathrm{P}_{\mathrm{v}}$; $\mathbf{d}$ Variation of states $\Delta \mathrm{P}_{\mathrm{m}}$

$$
J=\int_{0}^{t}\left(X^{T} Q X+u^{T} R u\right) d t
$$

Following [6], the optimal gain is the solution of the Algebraic Riccati Equation given by

$$
P A+A^{T} P-P B R^{-1} B^{T} P+Q=0
$$

As is clear from (5), the LQR presupposes the ready availability of $\mathrm{Q}$ and $\mathrm{R}$, which are difficult to specify for a given system. Assuming that all states are measurable, the control strategy $u=-K^{T} X$ places poles to stabilize the system. In the state feedback design as outlined above, it is assumed that all state variables are readily available for feedback. However, in practice, not all state variables are directly measurable in the case of large systems while any measurements would contain noise. Thus, it becomes imperative to estimate unavailable state variables from the available measurements of state variables using a state observer $[9,15,20]$. The present paper proposes to use the Kalman Estimator for estimating states from the available measurement of frequency change. It also estimates the gain vector $K$ by augmenting the state vector with the $K$ vector given by

$$
X_{a}=[X, K]^{T}
$$

where $X_{a}$ represents the states of the new augmented system.

\section{Estimation of augmented state and feedback gain - extended Kalman filter-based approach}

It is also interesting to note that LQR-based computation of $\mathrm{K}$ restricts the control to those cases where the system parameters are available. Alternatively, by estimating the states continuously from available measurements of some of the states, it will be possible to accommodate the dynamic changes of the system parameters.

The available measurements are given to the observer, where the Kalman estimator estimates the states $\mathrm{X}$ of the system [15] along with $\mathrm{K}$, by minimizing the difference between the measurements and the values computed from the state estimates. Finally, $u=-K^{T} X$ is used to stabilize the system. Figure 2 illustrates the approach.

Table 1 Mean and variance of state variables estimated corresponding to a measurement noise variance of 0.005

\begin{tabular}{llll}
\hline $\mathbf{K}$ & State variable & Mean & Variance \\
\hline$[2.999,1.000,-80.002]$ & $\Delta \mathrm{P}_{\mathrm{v}}$ & 0.0634 & $4.0817 \times 10^{-4}$ \\
& $\Delta \mathrm{P}_{\mathrm{m}}$ & 0.0635 & $4.2357 \times 10^{-4}$ \\
& $\Delta f$ & -0.0040 & $1.6709 \times 10^{-6}$ \\
& $\mathrm{~K} 1$ & 2.9999 & $1.3138 \times 10^{-9}$ \\
& $\mathrm{~K} 2$ & 1.0000 & $7.0250 \times 10^{-11}$ \\
& $\mathrm{~K} 3$ & -80.0002 & $9.3576 \times 10^{-9}$ \\
\hline
\end{tabular}




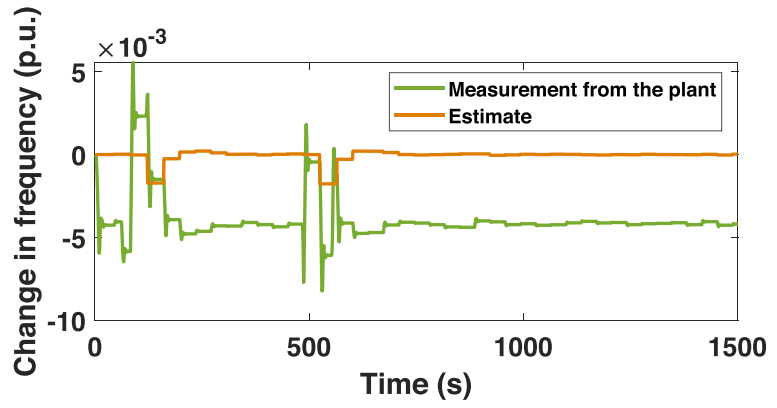

(a)

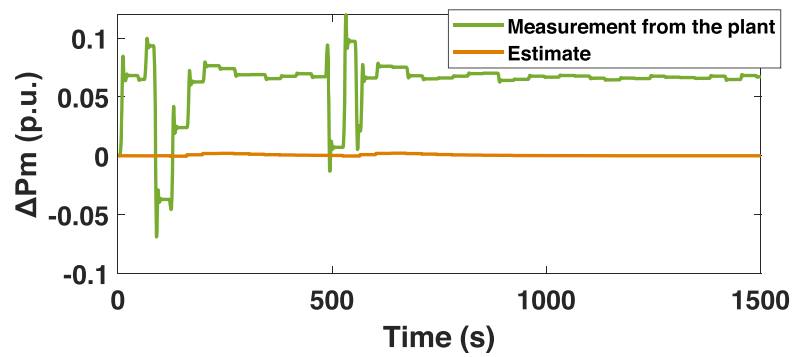

(c)

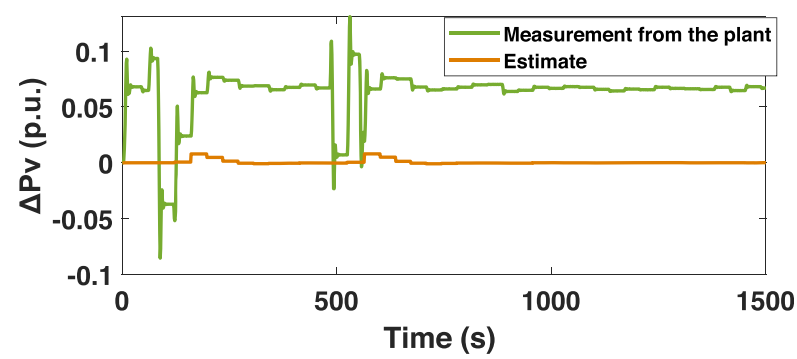

(b)

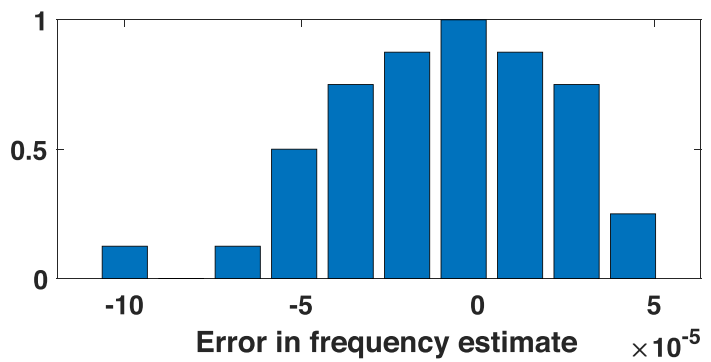

(d)

Fig. $\mathbf{6} \mathbf{a}, \mathbf{b}$ and $\mathbf{c}$ Variation of states $\Delta f, \Delta \mathrm{P}_{v}$ and $\Delta \mathrm{P}_{\mathrm{m}}$ in response to disturbance along with the estimate from the observer; $\mathbf{d}$ Normalized histogram of error in frequency estimate for a measurement noise variance of 0.005

\subsection{Kalman estimator}

The Kalman Filter provides a recursive statistical framework for estimation and prediction of the state of a process, given a mathematical model of that process [21]. The Kalman Filter estimates the process state by minimizing the mean of the squared estimate error $\left(z_{(k)}-H^{T} X_{(k)}\right)$. In doing so, the goal of the Kalman Filter is to minimize the estimate error covariance as

$$
P_{(k)}=E\left[\left(X_{a(k)}-\hat{X}_{a(k)}\right)\left(X_{a(k)}-\hat{X}_{a(k)}\right)^{T}\right]
$$

The posteriori state estimate $\hat{X}_{a(k \mid k)}$, based on the past $\mathrm{k}$ observations, gives the mean of the state distribution, i.e., $E\left(X_{a(k)}\right)$, and is computed as

$$
\hat{X}_{a(k \mid k)}=X_{a(k \mid k-1)}+L_{k}\left(z_{k}-H^{T} X_{a(k)}\right)
$$

The difference $\left(z_{(k)}-H^{T} X_{(k)}\right)$ is called the measurement innovation, or the residual, and reflects the discrepancy between predicted measurement and the actual measurement. $\mathrm{L}_{(\mathrm{k})}$ is the Kalman gain given by

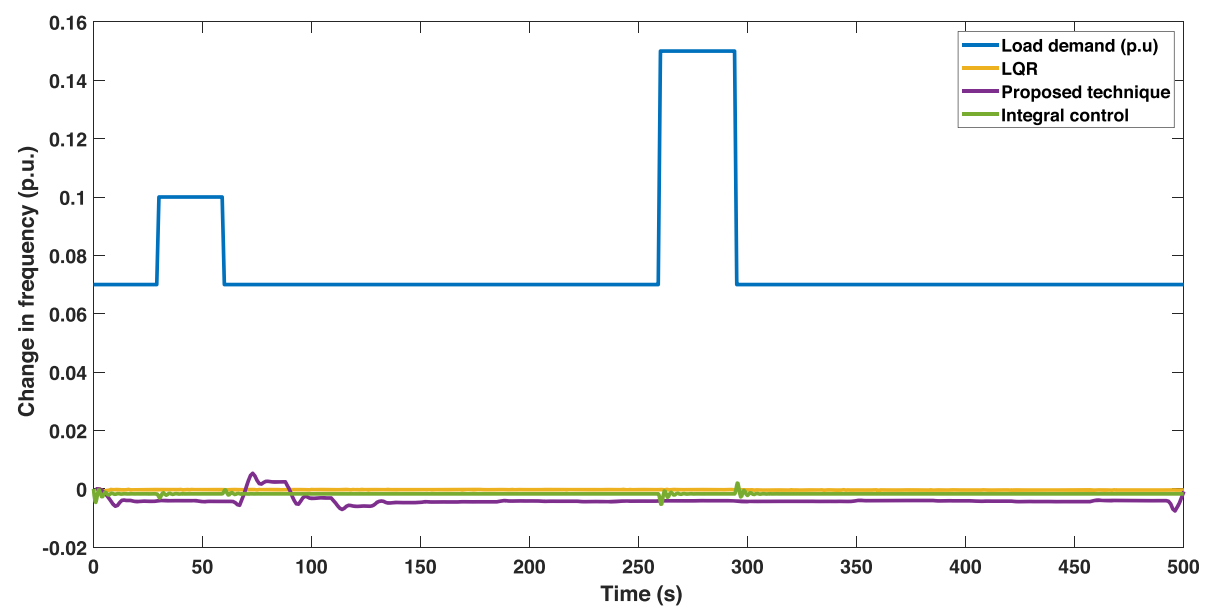

Fig. 7 Comparison of frequency deviation with the application of integral control, LQR and proposed technique for a measurement noise variance of 0.005 
Table 2 Performance comparison of controllers corresponding to a measurement noise variance of 0.005

\begin{tabular}{llll}
\hline Controller & Steady state error (p.u.) & Variance & $\begin{array}{l}\text { Computational } \\
\text { time (s) }\end{array}$ \\
\hline Integral & -0.007 & $3.49 \times 10^{-7}$ & 2.56377 \\
LQR & $-3 \times 10^{-4}$ & $2.16 \times 10^{-8}$ & 14.9660 \\
Proposed & $-4 \times 10^{-3}$ & $1.67 \times 10^{-6}$ & 1.70527 \\
\hline
\end{tabular}

$$
L_{(k)}=P_{(k / k-1)} H^{T}\left(H P_{(k / k-1)} H^{T}+R_{(k)}\right)^{-1}
$$

where $\mathrm{R}(\mathrm{k})$ is the measurement error covariance.

The state covariance $P_{(k / k-1)}$ is updated as

$$
P_{(k / k)}=\left(I-L_{k} H\right) \mathrm{P}_{(k / k-1)}
$$

\section{Proposed load frequency control}

As explained in Section 2, the LFC controls the states of a system based on the measurement of the frequency change in the power system, considering the changes in the system dynamics. Though the problem is best addressed in the context of optimal control theory [18], limitation in obtaining the accurate real time measurements of all state variables which are required to estimate the unknown states, using the measured frequency values and the system model [22]. Considering the augmented states, the system model is modified as two sets of equations shown in (11) and (13), as

$$
X_{(k+1)}=\left(A-B K^{T}\right) X_{(k)}
$$

where

$$
X_{k}=\left[\Delta P_{v}, \Delta P_{m}, \Delta f\right]
$$

$\Delta \mathrm{P}_{\mathrm{v}}$ : real power command in p.u.

$\Delta \mathrm{P}_{\mathrm{m}}$ : resulting deviation in mechanical power in p.u.

$\Delta \mathrm{f}$ : the change in frequency in p.u.

$$
\begin{aligned}
& K_{(k+1)}=K_{(k)} \\
& z_{k}=\left[\begin{array}{llllll}
0 & 0 & 1 & 0 & 0 & 0
\end{array}\right] X_{a(k)}=H^{T} X_{a(k)}
\end{aligned}
$$

From (11) it can be seen that the system is non-linear as $\mathrm{X}$ and $\mathrm{K}$ are now the states of the augmented system and hence the Extended Kalman Filter (EKF) [23, 24] is used to compute the updates of the augmented state vector $X_{\mathrm{a}}$.

The update equations of EKF $[25,26]$ are modified accordingly as (17)-(27). While the measurement Jacobian $\mathrm{H}(\mathrm{k})$ is the same as $\mathrm{H}$ given in (14), the Jacobian of the state model takes the following structure [21], as

(i) (i)The product terms involved in the equation

$$
X_{(k+1)}=\left(A-B K^{T}\right) X_{(k)}+G \omega_{(k)}
$$

(ii) The identity nature of $K_{(k+1)}=K_{k}$

$$
F_{k}=\frac{\partial F}{\partial X_{a(k)}}=\left[\begin{array}{cc}
{\left[A-B K^{T}\right]} & -B X^{T} \\
0 & I
\end{array}\right]
$$

The instantaneous measurements of $\Delta \mathrm{f}$ from the plant

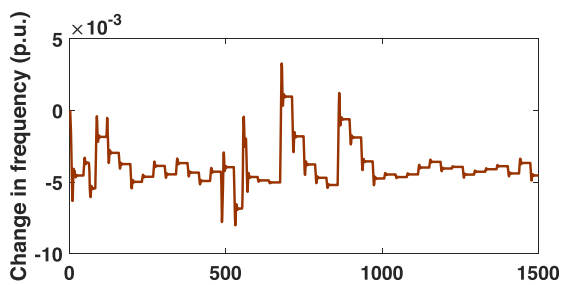

(b)

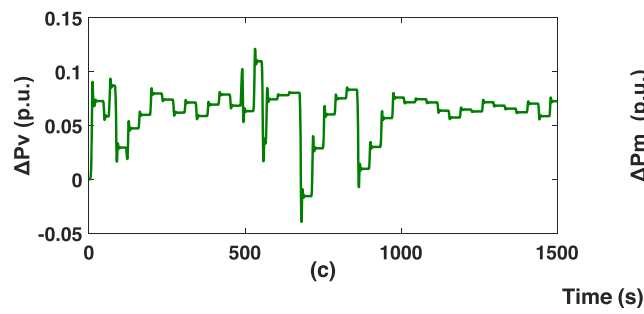

Fig. 8 System response during changes in demand with frequency measurement noise variance of 0.01. a Variation in $\Delta f_{\text {, }} \mathbf{b}$ frequency response during control action; c Variation of states $\Delta \mathrm{P}_{\mathrm{v}}$; $\mathbf{d}$ Variation of states $\Delta \mathrm{P}_{\mathrm{m}}$ 
Table 3 Mean and the variance of state variables estimated corresponding to a measurement noise variance of 0.01

\begin{tabular}{llll}
\hline $\mathbf{K}$ & State variable & Mean & Variance \\
\hline$[3.0007,0.9998,-80.0015]$ & $\Delta \mathrm{P}_{\mathrm{v}}$ & 0.0635 & $3.8767 \times 10^{-4}$ \\
& $\Delta \mathrm{P}_{\mathrm{m}}$ & 0.0636 & $3.9950 \times 10^{-4}$ \\
& $\Delta f$ & -0.0040 & $1.5726 \times 10^{-6}$ \\
& $\mathrm{~K} 1$ & 3.0004 & $1.1718 \times 10^{-7}$ \\
& $\mathrm{~K} 2$ & 0.9999 & $5.4111 \times 10^{-9}$ \\
& $\mathrm{~K} 3$ & -80.0002 & $5.2235 \times 10^{-7}$ \\
& & &
\end{tabular}

are given to the EKF to estimate the states including the $\mathrm{K}$, while applying the control of $u=-K^{T} X$ continuously.

State model:

$$
\begin{aligned}
& X_{k}=\left[\Delta P_{v}, \Delta P_{m}, \Delta f\right] \\
& X_{(k+1)}=\left(A-B K^{T}\right) X_{k} ; K_{(k+1)}=K_{(k)}, \\
& X_{a(k+1)}=F X_{a(k)}+G \omega_{(k)}
\end{aligned}
$$

where $X_{a}=[X, K]^{T}$ and $\mathrm{G}$ is the disturbance vector of dimension $2 \mathrm{n}$.

Measurement equation:

$$
z_{k}=\left[\begin{array}{llllll}
0 & 0 & 1 & 0 & 0 & 0
\end{array}\right] X_{a(k)}=H^{T} X_{a k}+v_{k}
$$

$G \omega_{(k)}$ accounts for the plant disturbance and $v_{k}$ the measurement noise.

Correction update:

$$
X_{a(k \mid k)}=X_{a(k \mid k-1)}+L_{k}\left(z_{(k)}-H X_{a(k)}\right)
$$

where $L_{k}$ is given by

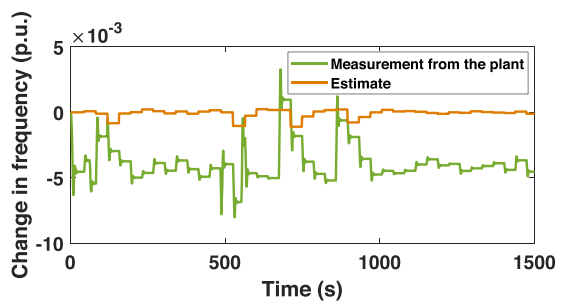

(a)

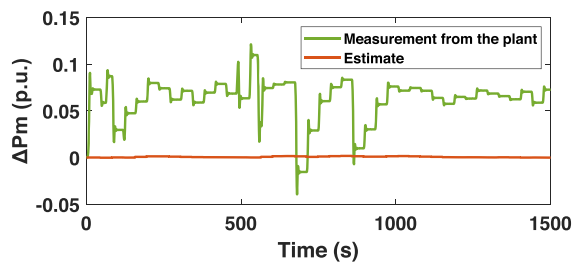

(c)

$$
L_{k}=P_{(k \mid k-1)} H^{T}\left(H P_{(k \mid k-1)} H^{T}+R_{k}\right)^{-1}
$$

where

$$
\begin{aligned}
& H_{k}=\frac{\partial H}{\partial X_{a(k)}} \\
& R_{k}=E\left(v^{2}\right) \\
& P_{(k \mid k-1)}=F_{k} P_{(k-1 \mid k-1)} F_{k}^{T}+Q \\
& F_{k}=\frac{\partial F}{\partial X_{a(k)}} \\
& Q=E\left(\omega^{2}\right) G G^{T}
\end{aligned}
$$

\section{Results and discussion}

Following the linearized single-area power system outlined in [6], the proposed algorithm is simulated in MATLAB R2018a, where the single-area power system has the following components:

1. A governor with transfer function $\frac{1}{\left(1+\mathrm{s} T_{g}\right)}$;

2. Load and machines with transfer function $\frac{1}{(2 \mathrm{Hs}+\mathrm{D})}$;

3. Droop characteristic $\frac{1}{\mathrm{R}}$;

4. A non-reheated turbine with transfer function $\frac{1}{\left(1+\mathrm{s} T_{t}\right)}$;

The components are interconnected as shown in Fig. 3. $\mathrm{R}$ is the speed regulation of the governor, and $\mathrm{T}_{\mathrm{g}}$ and $\mathrm{T}_{\mathrm{t}}$ are the governor and turbine time constants, respectively. $\mathrm{H}$ is the inertia constant and $\mathrm{D}$ the frequency sensitive load coefficient. $\Delta \mathrm{P}_{\mathrm{v}}$ is the real power command and $\Delta \mathrm{P}_{\mathrm{m}}$ is the change in mechanical power. $\Delta \mathrm{f}$ is the change in frequency, $\Delta \mathrm{P}_{\mathrm{L}}$ is the change in load and $\Delta \mathrm{P}_{\text {ref }}$ the reference signal.

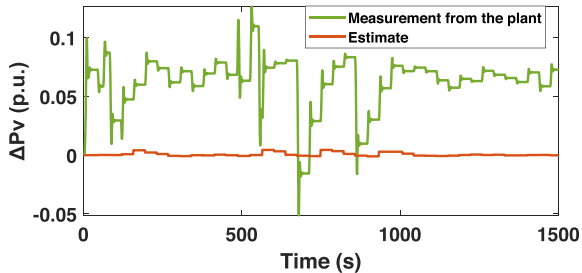

(b)

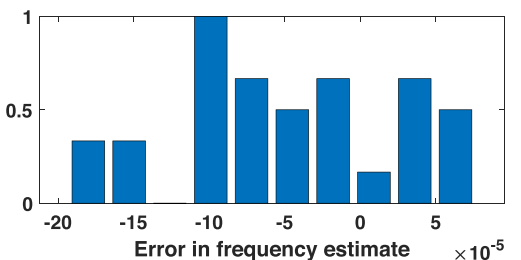

(d)

Fig. 9 a, $\mathbf{b}$ and $\mathbf{c}$ Variation of states $\Delta f, \Delta P_{v}$ and $\Delta P_{m}$ in response to disturbance along with the estimate from the observer (d) Normalized histogram of error in frequency estimate for a measurement noise variance of 0.01 


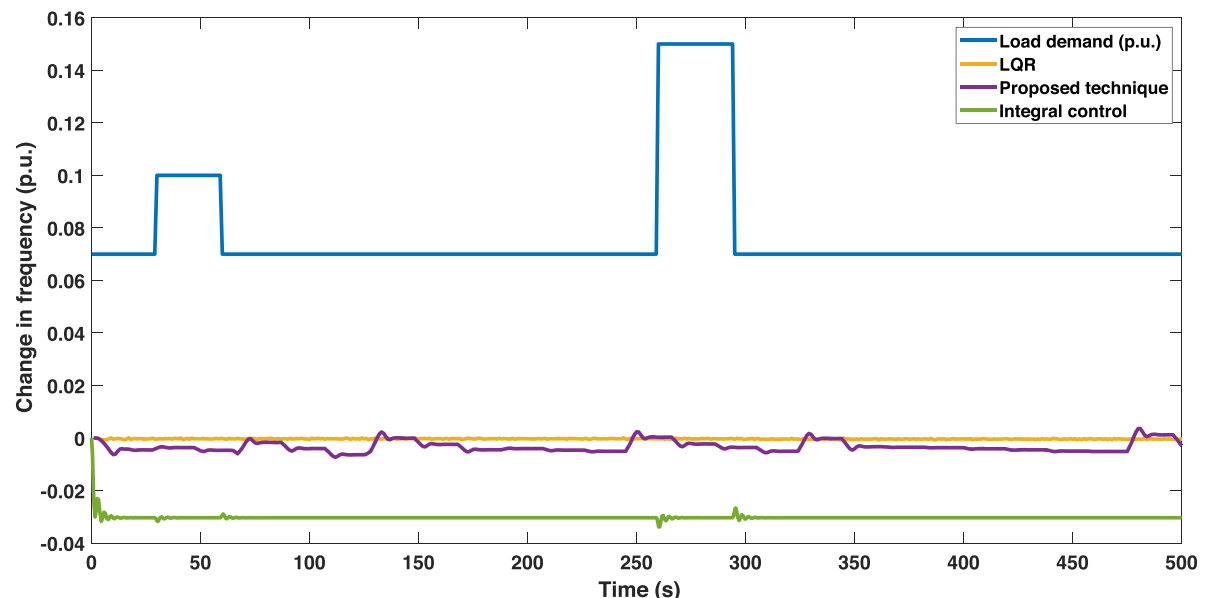

Fig. 10 Comparison of frequency deviation of the system considered with the application of integral control, LQR and proposed technique for a measurement noise variance of 0.01

As shown in Fig. 3, the measured values of $\Delta \mathrm{f}$ are provided for the EKF estimator to estimate the states. The detailed derivation of the state space model of the single-area power system shown in Fig. 3 [6] is given in the Appendix. The augmented linearized discrete model of the single-area power system [6] is described by

$$
A=\left[\begin{array}{cccccccc}
0.6041 & -0.0397 & -7.8288 & 0 & 0 & 0 \\
0.1413 & 0.8161 & -0.7935 & 0 & 0 & 0 \\
0.0008 & 0.0090 & 0.9892 & 0 & 0 & 0 \\
& 0 & 0 & 0 & & 1 & 0 & 0 \\
& 0 & 0 & 0 & & 0 & 1 & 0 \\
& 0 & 0 & 0 & & 0 & 0 & 1
\end{array}\right]
$$

$$
\begin{aligned}
& B=\left[\begin{array}{c}
0.04250 \\
0.0028 \\
-0.0100 \\
0 \\
0 \\
0
\end{array}\right] \\
& \mathrm{H}=\left[\begin{array}{llll}
0 & 0 & 1 & 0
\end{array}\right] \\
& \mathrm{R}=0.001
\end{aligned}
$$

$$
Q=\left[\begin{array}{cccccccc}
0.001 & 0 & 0 & & 0 & 0 & 0 & \\
0 & 0.001 & 0 & & 0 & 0 & 0 & \\
0 & 0 & 0.001 & 0 & 0 & 0 & \\
& 0 & 0 & 0 & 0.001 & 0 & 0 \\
& 0 & 0 & 0 & & 0 & 0.001 & 0 \\
& 0 & 0 & 0 & & 0 & 0 & 0.001
\end{array}\right]
$$

The power system model in MATLAB / Simulink is shown in Fig. 4, in which the MATLAB function "COMBINED ESTIMATION" performs a continuous estimation of both the state $\mathrm{X}$ and the feedback gain $\mathrm{K}$. For all simulations explained below, a sudden increase in demand is injected (i) after $30 \mathrm{~s}$ and (ii) $500 \mathrm{~s}$ from the commencement of simulation, while each of the increases in demand exists for a duration of $30 \mathrm{~s}$.

\subsection{Case I}

The noise in the frequency measurement is assumed to have a variance of 0.005 . The corresponding variation in the frequency output of the power system shown in Fig. 5 confirms that the control is effective to bring down $\Delta \mathrm{f}$ to a range of $\pm 1.6709 \times 10^{-6}$ within $50 \mathrm{~s}$ after the change in demand is removed. Thereafter the system continuously

Table 4 Performance comparison of controllers corresponding to a measurement noise variance of 0.01

\begin{tabular}{llll}
\hline Controller & $\begin{array}{l}\text { Steady state } \\
\text { error (p.u.) }\end{array}$ & Variance & $\begin{array}{l}\text { Computational } \\
\text { time (s) }\end{array}$ \\
\hline Integral & -0.03 & $1.12 \times 10^{-6}$ & 3.31081 \\
LQR & $-2 \times 10^{-4}$ & $2.19 \times 10^{-8}$ & 14.0762 \\
Proposed & $-5 \times 10^{-3}$ & $1.57 \times 10^{-6}$ & 1.3579 \\
\hline
\end{tabular}




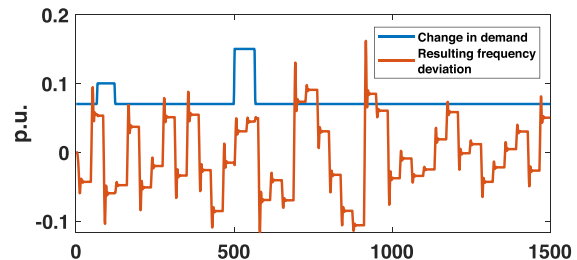

(a)

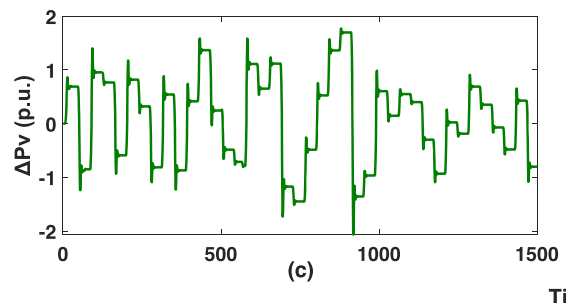

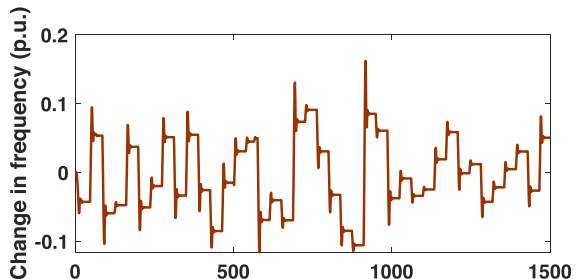

(b)

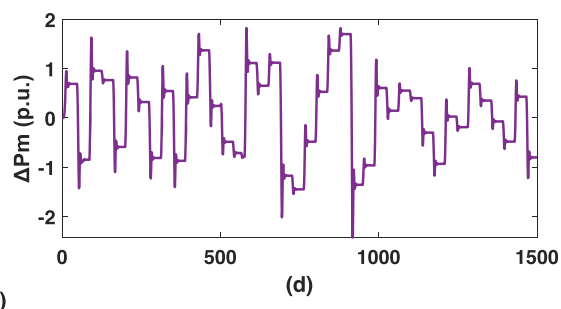

Fig. 11 System response during changes in demand and frequency measurement noise variance of 0.1: a Variation in $\Delta$; $\mathbf{b}$ Frequency response during control action; $\mathbf{c}$ Variation of states $\Delta \mathrm{P}_{\mathrm{v}}$; $\mathbf{d}$ Variation of states $\Delta \mathrm{P}_{\mathrm{m}}$

corrects the gain value while estimating the states so that during the occurrence of a second disturbance at $500 \mathrm{~s} \Delta \mathrm{f}$ remains fully within the limits mentioned above. The mean value and the variance of each of the state variables after stabilization, for different levels of measurement noise injected, are shown in Table 1. Variations of other states $\Delta \mathrm{P}_{\mathrm{v}}$ and $\Delta \mathrm{P}_{\mathrm{m}}$ in response to change in demand are shown in Fig. 5(c) and (d), respectively.

It is interesting to note that $\Delta \mathrm{P}_{\mathrm{v}}$ and $\Delta \mathrm{P}_{\mathrm{m}}$ also increase initially to meet the increase in demand, but are stabilized after the second spurt in demand to values within $\pm 4.0817 \times 10^{-4}$ and $\pm 4.2357 \times 10^{-4}$, respectively.

Estimated values of state variables plotted along with the measurements from the plant are shown in Fig. 6 (a), (b) and (c). The corresponding normalized histogram in frequency estimate confirming the merit of estimation is shown in Fig. 6 (d). Figure 7 compares the control action of the proposed technique with conventional integral control and LQR for the noise variance of 0.005 . With reference to Table 2, it is evident that the proposed control has better computational time compared to the integral controller and LQR.

\subsection{Case II}

The noise in frequency measurement is assumed to have a variance of 0.01 . Here again the system continuously corrects the gain values while estimating the states, so that $\Delta \mathrm{f}$ stabilizes to $\pm 1.5726 \times 10^{-6}$ as shown in Fig. 8 .

As in the previous case the continuous control keeps $\Delta \mathrm{f}$ well within the limits during the second disturbance. The mean value and the variance of each of the state variables after stabilization for different levels of measurement noise injected are shown in Table 3.

Variations of other states $\Delta \mathrm{P}_{\mathrm{v}}$ and $\Delta \mathrm{P}_{\mathrm{m}}$ in response to change in demand are shown in Fig. 8(c) and (d), respectively. It is noted that $\Delta \mathrm{P}_{\mathrm{v}}$ and $\Delta \mathrm{P}_{\mathrm{m}}$ also increase initially to meet the increase in demand; but are gradually stabilized to values within $\pm 3.8767 \times 10^{-4}$ and \pm $3.9950 \times 10^{-4}$, respectively after the second spurt in demand. Estimated values of state variables plotted along with the measurements from the plant are shown in Fig. 9 (a), (b) and (c). The corresponding normalized histogram in frequency estimate confirming the merit of estimation is shown in Fig. 9 (d).

The control actions of the proposed technique and the conventional integral control and LQR for a noise variance of 0.01 are compared in Fig. 10. With reference to Table 4, it is clear that the proposed control has better computational time compared to the integral controller and LQR.

\subsection{Case III}

The noise in frequency measurement is assumed to have a variance of 0.1 . Here again the system continuously corrects the gain values while estimating the states, so that $\Delta \mathrm{f}$ stabilizes to $\pm 1.023 \times 10^{-6}$ as shown in Fig. 11 .

It can be seen that the increase in the measurement noise affects the variance in the estimate of all the state variables. However, as in the previous cases, the

Table 5 Mean and variance of state variables estimated corresponding to a measurement noise variance of 0.1

\begin{tabular}{llll}
\hline $\mathbf{K}$ & State variable & Mean & Variance \\
\hline$[2.9943,0.9940,-80.6344]$ & $\Delta \mathrm{P}_{\mathrm{v}}$ & 0.1284 & 0.5515 \\
& $\Delta \mathrm{P}_{\mathrm{m}}$ & 0.1282 & 0.5677 \\
& $\Delta \mathrm{f}$ & -0.0080 & $1.023 \times 10^{-6}$ \\
& $\mathrm{~K} 1$ & 2.9935 & $6.9818 \times 10^{-5}$ \\
& $\mathrm{~K} 2$ & 0.9941 & $2.6252 \times 10^{-5}$ \\
& $\mathrm{~K} 3$ & -80.3066 & 0.0602 \\
\hline
\end{tabular}




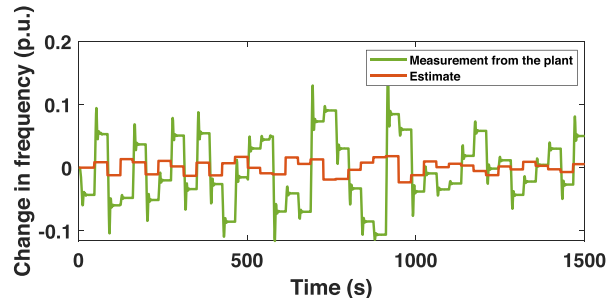

(a)

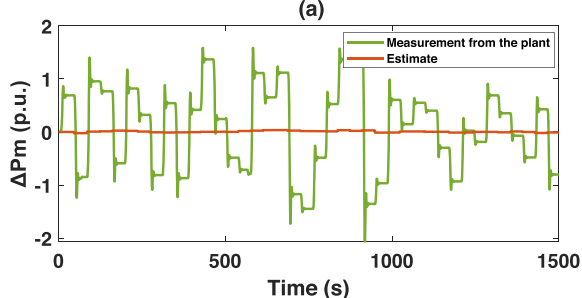

(c)

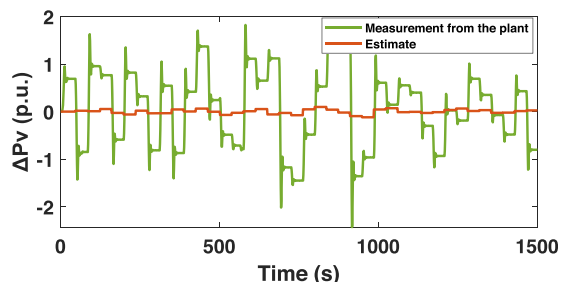

(b)

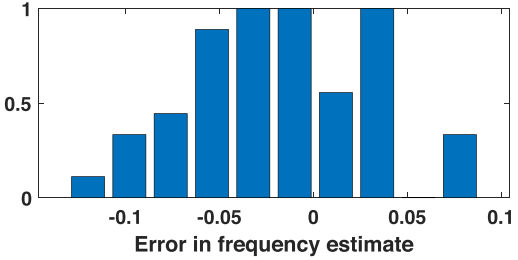

(d)

Fig. 12 a, $\mathbf{b}$ and $\mathbf{c}$ Variation of states $f_{,} P_{v}$ and $P_{m}$ in response to disturbance along with the estimate from the observer; $\mathbf{d}$ Normalized histogram of error in frequency estimate for a measurement noise variance of 0.1

continuous control keeps $\Delta \mathrm{f}$ well within the limits during the second disturbance. The mean value and the variance of each of the state variables after stabilization for different levels of measurement noise injected, are shown in the Table 5, while variations of other states $\Delta \mathrm{P}_{\mathrm{v}}$ and $\Delta \mathrm{P}_{\mathrm{m}}$ are shown in Fig. $11(\mathrm{c})$ and (d), respectively. It can be noted that $\Delta \mathrm{P}_{\mathrm{v}}$ and $\Delta \mathrm{P}_{\mathrm{m}}$ also increase initially to meet the increase in demand; but are stabilized to values within \pm 0.5515 and \pm 0.5677 , respectively after the second spurt in demand. It can be seen that the states stabilize within a variance of $\pm \sigma$ in all cases, while the gain $K$ shows little variation from the mean value.

Estimated values of state variables plotted along with the measurements from the plant are shown in Fig. 12 (a), (b) and (c). The corresponding normalized histogram in frequency estimate confirming the merit of estimation is shown in Fig. 12 (d). Figure 13 compares the control actions of the proposed technique with the conventional integral control and LQR for a noise variance of 0.1. It is noted that the corresponding poles placed in the system also stabilize around mean values with variances as shown in Table 6.

Table 7 compares these controllers in terms of steady state error, variance and computational time. It can be seen that for high measurement noise variance, the proposed technique performs well in comparison to others, as integral controller and LQR show higher steady state errors. Since the measurements are corrupted by high noise variance, additional tuning is required for these controllers to bring back the offset to zero. This is avoided with the proposed technique.

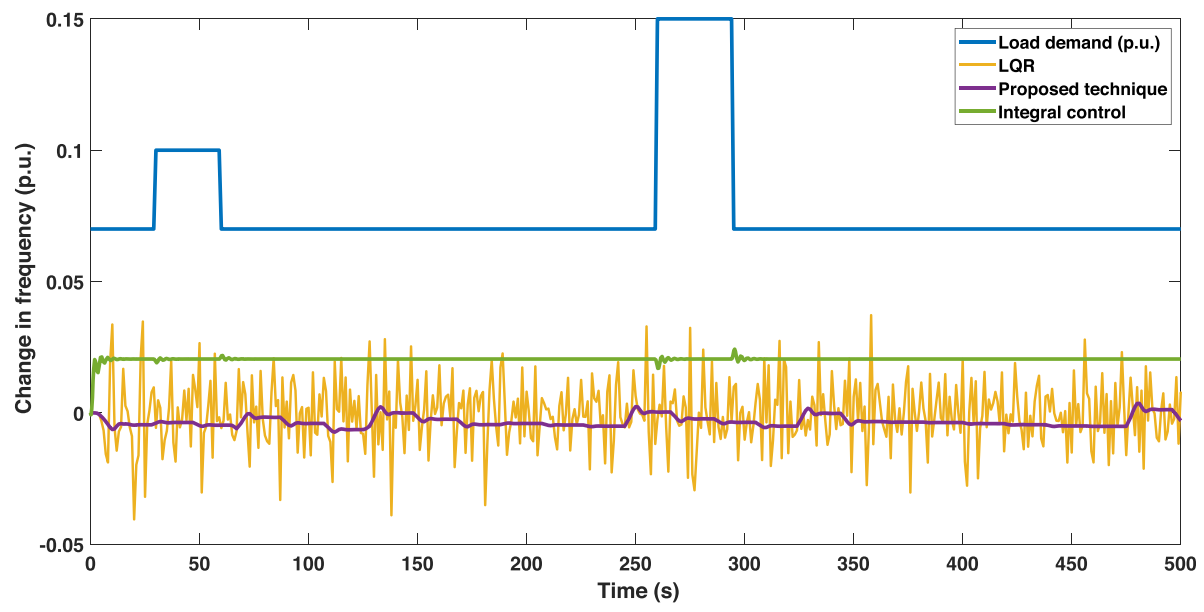

Fig. 13 Comparison of frequency deviation of the system considered with the application of integral control, LQR and proposed technique for a measurement noise variance of 0.1 
Table 6 Resulting pole placement for the feedback control

\begin{tabular}{|c|c|c|c|c|c|c|}
\hline \multirow[b]{2}{*}{ Poles } & \multicolumn{2}{|c|}{$\begin{array}{l}\text { Measurement noise } \\
\text { variance }=0.005\end{array}$} & \multicolumn{2}{|c|}{$\begin{array}{l}\text { Measurement noise } \\
\text { variance }=0.01\end{array}$} & \multicolumn{2}{|c|}{$\begin{array}{l}\text { Measurement noise } \\
\text { variance }=0.1\end{array}$} \\
\hline & Mean & Variance & Mean & Variance & Mean & Variance \\
\hline \multirow[t]{2}{*}{1} & -6.0424 & $1.2244 \times 10^{-11}$ & -6.0426 & $1.2479 \times 10^{-8}$ & -6.0595 & $2.0212 \times 10^{-4}$ \\
\hline & +j4.8839 & $+\mathrm{j} 1.6562 \times 10^{-9}$ & $+\mathrm{j} 4.8845$ & $+\mathrm{j} 1.4642 \times 10^{-7}$ & $+\mathrm{j} 4.8720$ & $+j 1.1398 \times 10^{-4}$ \\
\hline \multirow[t]{2}{*}{2} & -6.0424 & $1.2244 \times 10^{-11}$ & -6.0426 & $1.2479 \times 10^{-8}$ & -6.0595 & $2.0212 \times 10^{-4}$ \\
\hline & $-j 4.8839$ & $+\mathrm{j} 1.6562 \times 10^{-9}$ & $-j 4.8845$ & $+\mathrm{j} 1.4642 \times 10^{-7}$ & $-j 4.8720$ & $+j 1.1398 \times 10^{-4}$ \\
\hline 3 & $-2.9952+j 0$ & $3.6999 \times 10^{-11}+\mathrm{j} 0$ & $-2.9950+\mathrm{j} 0$ & $2.2913 \times 10^{-8}+j 0$ & $-2.9917+\mathrm{j} 0$ & $2.1535 \times 10^{-5}+\mathrm{j} 0$ \\
\hline
\end{tabular}

\section{Extension to MIMO systems}

The techniques demonstrated so far are directly applicable for SISO systems, where $\mathrm{K}$ will be a $(\mathrm{n} \times 1)$ vector. However, for MIMO systems as in the case of a multi-area power system, $\mathrm{K}$ will be a matrix as shown in (3). By arranging the elements of the $(n \times p)$ matrix as a $(n p \times 1)$ vector and augmenting it to the state vector $\mathrm{X}$, the proposed approach can be extended to MIMO systems. The dimensions of the matrices such as $\mathrm{F}_{\mathrm{k}}$ in (17), $\mathrm{P}_{(\mathrm{k} \mid \mathrm{k})}$ in (10) and $\mathrm{H}$ in (24) will increase, but can be handled in the implementation easily by taking note of the sparse nature of the matrices.

\section{Conclusion}

This paper has demonstrated a new observer-based approach for implementing the LFC in power systems. The EKF based observer continuously estimates the gains and the states based on the measurement of shift in frequency. Simulations are carried out in a single-area power system in MATLAB/SIMULINK, in which the observer implemented as a separate MATLAB code is plugged into the system to sample the output from the power system and inject the control back. The performance of the implemented LFC is tested by injecting a sudden change in demand lasting for $30 \mathrm{~s}$. The power system is stabilized within $\pm \sigma$ after each change in demand, thereby ascertaining the effectiveness of the control strategy.

\section{Appendix}

In this section, a simplified frequency response model for a single-area power system with generator, along with a turbine and governor, is chosen for illustration.

Following [6], the s domain equations for the block diagram shown are given below:

Table 7 Performance comparison of controllers corresponding to a measurement noise variance of 0.1

\begin{tabular}{llll}
\hline Controller & $\begin{array}{l}\text { Steady state } \\
\text { error (p.u.) }\end{array}$ & Variance & $\begin{array}{l}\text { Computational } \\
\text { time (s) }\end{array}$ \\
\hline Integral & 0.021 & $1.32 \times 10^{-4}$ & 2.5230 \\
LQR & \pm 0.04 & 0.0126 & 13.2677 \\
Proposed & $-7 \times 10^{-3}$ & $1.57 \times 10^{-6}$ & 1.1353 \\
\hline
\end{tabular}

$$
\begin{aligned}
& \left(1+s T_{g}\right) \Delta \mathrm{P}_{v(s)}=\Delta P_{r e f}-\frac{1}{R} \Delta f(s) \\
& \left(1+s T_{t}\right) \Delta P_{m(s)}=\Delta P_{v} \\
& (2 H s+D) \Delta f(s)=\Delta P_{m}-\Delta P_{L}
\end{aligned}
$$

Solving the first derivative term yields

$$
s \Delta P_{v}(s)=\frac{-1}{T_{g}} \Delta P_{v}-\frac{1}{R T_{g}} \Delta f(s)+\frac{1}{T_{g}} \Delta P_{r e f}(s)
$$

$$
\begin{aligned}
& s \Delta P_{m}(s)=\frac{1}{T_{t}} \Delta P_{v}-\frac{1}{T_{t}} \Delta P_{m} \\
& s \Delta f(s)=\frac{1}{2 H} \Delta P_{m}-\frac{D}{2 H} \Delta f(s)-\frac{1}{2 H} \Delta P_{L} \\
& {\left[\begin{array}{c}
\Delta P_{v} \\
\Delta P_{m} \\
\Delta f
\end{array}\right]=\left[\begin{array}{ccc}
\frac{1}{T_{g}} & 0 & \frac{-1}{R T_{g}} \\
\frac{1}{T_{t}} & \frac{-1}{T_{t}} & 0 \\
0 & \frac{1}{2 H} & \frac{-D}{2 H}
\end{array}\right]\left[\begin{array}{c}
\Delta P_{v} \\
\Delta P_{m} \\
\Delta f
\end{array}\right]+\left[\begin{array}{c}
0 \\
0 \\
\frac{-1}{2 H}
\end{array}\right] \Delta P_{L}+\left[\begin{array}{c}
\frac{1}{T_{g}} \\
0 \\
0
\end{array}\right] \Delta P_{r e f}}
\end{aligned}
$$

System matrix,

Table 8 System parameters

\begin{tabular}{ll}
\hline Variable & Value \\
\hline Turbine Time Constant (Tt), s & 0.5 \\
Governor Time Constant (Tg), s & 0.2 \\
Inertia Constant (H) & 5 \\
Speed Regulation (R), p.u. & 0.05 \\
Frequency Sensitive Load Coefficient (D) & 0.8 \\
Nominal Frequency (f),Hz & 60 \\
Base Power (S), MVA & 1000 \\
\hline
\end{tabular}




$$
A=\left[\begin{array}{ccc}
\frac{1}{T_{g}} & 0 & \frac{-1}{R T_{g}} \\
\frac{1}{T_{t}} & \frac{-1}{T_{t}} & 0 \\
0 & \frac{1}{2 H} & \frac{-D}{2 H}
\end{array}\right]
$$

A typical power system with parameters described above for constructing $\mathrm{A}$ and $\mathrm{B}$ matrices is shown in Table 8.

For the purpose of discrete simulations, $\mathrm{A}$ and $\mathrm{B}$ are discretized as

$$
\begin{aligned}
& A=\left[\begin{array}{ccc}
0.6041 & -0.0397 & -7.8288 \\
0.1413 & 0.8161 & -0.7935 \\
0.0008 & 0.0090 & 0.9892
\end{array}\right] \\
& B=\left[\begin{array}{c}
0.04250 \\
0.0028 \\
-0.0100
\end{array}\right]
\end{aligned}
$$

\section{Abbreviations}

AGC: Automatic Generation Control; EKF: Extended Kalman Filter; LFC: Load Frequency Control; LQR: Linear Quadratic Regulator; MIMO: Multiple Input Multiple Output; SISO: Single Input Single Output

\section{Acknowledgements}

Not applicable

\section{Authors' contributions}

Corresponding author contributed to the research, manuscript preparation and submission. Co-authors guided the work and supervised in manuscript revision, advice and professional support to the corresponding author. The author(s) read and approved the final manuscript.

\section{Funding}

Funding information is not applicable / No funding was received.

\section{Availability of data and materials}

Data sharing not applicable to this article as no datasets were generated or analysed during the current study.

\section{Competing interests}

The authors declare that they have no competing interests.

Received: 29 December 2019 Accepted: 29 September 2020 Published online: 09 November 2020

\section{References}

1. Concordia, C., \& Kirchmayer, L. K. (1953). Tie-line power and frequency control of electric power systems. Transactions of the American Institute of Electrical Engineers Part III: Power Apparatus and Systems, 72(3), 562-572.

2. Annamraju, A., \& Nandiraju, S. (2019). Robust frequency control in a renewable penetrated power system: An adaptive fractional order-fuzzy approach. Protection and Control of Modern Power Systems, 4(1), 1-15.

3. Magdy, G., Shabib, G., Elbaset, A. A., \& Mitani, Y. (2018). Optimized coordinated control of LFC and SMES to enhance frequency stability of a real multi-source power system considering high renewable energy penetration. Protection and Control of Modern Power Systems, 3(1), 1-15.

4. Cohn, N. (1956). Some aspects of tie-line bias control on interconnected power systems. Transactions of the American Institute of Electrical Engineers Part III: Power Apparatus and Systems, 75(3), 1415-1436.

5. Kothari, D. P., \& Nagrath, I. J. (2003). Modern power system analysis. New Delhi: Tata McGraw- Hill Publishing Company.

6. Saadat, H. (2002). Power system analysis. New York: McGraw-Hill.
7. Pandey, S. K., Mohanty, S. R., \& Kishor, N. (2013). A literature survey on load frequency control for conventional and distribution generation power systems. Renewable and Sustainable Energy Reviews, 25, 318-334.

8. Yamashita, K, \& Taniguchi, T. (1986). Optimal observer design for load-frequency control. International Journal of Electrical Power \& Energy Systems, 8(2), 93-100.

9. Mishra, S., Mallesham, G., \& Sekhar, P. (2013). Biogeography based optimal state feedback controller for frequency regulation of a smart microgrid. IEEE Transactions on Smart Grid, 4(1), 628-637.

10. Kirchmayer, L. K. (1959). Economic control of interconnected systems. New York: Wiley,

11. Cohn, N. (1967). Considerations in the regulation of interconnected areas. IEEE Transactions on Power Apparatus and Systems, AS-86(12), 1527-1538,

12. Ibraheem Kumar, P., \& Kothari, D. P. (2005). Recent philosophies of automatic generation control strategies in power systems. IEEE Transactions on Power Apparatus and Systems, 20(1), 346-357.

13. Bevrani, H., \& Hiyama, T. (2016). Intelligent automatic generation control. New York: CRC press.

14. Khooban, M. H., Niknam, T., Blaabjerg, F., \& Dragicevic, T. (2017). A new load frequency control strategy for microgrids with considering electrical vehicles. Electric Power Systems Research, 143, 585-598.

15. Shahalami, S. H., \& Farsi, D. (2018). Analysis of load frequency control in a restructured multi-area power system with the Kalman fiter and the LQR controller. AEU International Journal of Electronics and Communications, 86, 25-46.

16. Alhelou, H. H., Hamedani-Golshan, M. E., Zamani, R., Heydarian-Forushani, E., \& Siano, P. (2018). Challenges and opportunities of load frequency contro in conventional, modern and future smart power systems: A comprehensive review. Energies, 11(10), 1-35.

17. Kuo, B. C., \& Golnaraghi, M. (2009). Automatic control systems. Hoboken: Wiley

18. Ogata, K. (1997). Modern control systems. London: Prentice Hall.

19. Prajapat, G. P., Senroy, N., \& Kar, I. N. (2017). Stability enhancement of DFIGbased wind turbine system through linear quadratic regulator. IET Generation Transmission and Distribution, 12(6), 1331-1338.

20. Kanieski, J. M., Tambara, R. V., Pinheiro, H., Cardoso, R., \& Gruendling, H. A. (2016). Robust adaptive controller combined with a linear quadratic regulator based on Kalman filtering. IEEE Transactions on Automatic Control, 61(5), 1373-1378

21. Muso, H., \& Zarchan, P. (2005). Fundamentals of Kalman filtering: A practical approach. Virginia: American Institute of Aeronautics and Astronautics.

22. Tan, W., Chang, S., \& Zhou, R. (2017). Load frequency control of power systems with non-linearities. IET Generation Transmission and Distribution, 11(17), 4307-4313.

23. Zeng, N., Wang, Z., Li, Y., Du, M., \& Liu, X. (2012). A hybrid EKF and switching PSO algorithm for joint state and parameter estimation of lateral flow immunoassay models. IEEE/ACM Transactions on Computational Biology and Bioinformatics, 9(2), 321-329.

24. Usta, M. A., Okumus, H. I., \& Kahveci, H. (2017). A simplified three-level SVMDTC induction motor drive with speed and stator resistance estimation based on extended Kalman filter. Electrical Engineering, 99(2), 707-720.

25. Lamsal, D., Sreeram, V., Mishra, Y., \& Kumar, D. (2017). Kalman filter approach for dispatching and attenuating the power fluctuation of wind and photovoltaic power generating systems. IET Generation Transmission and Distribution, 12(7), 1501-1508.

26. Fan, L., \& Wehbe, Y. (2013). Extended Kalman filtering based real time dynamic state and parameter estimation using PMU data. Electric Power Systems Research, 103, 168-177.

\section{Submit your manuscript to a SpringerOpen ${ }^{\circ}$ journal and benefit from:}

- Convenient online submission

- Rigorous peer review

- Open access: articles freely available online

High visibility within the field

- Retaining the copyright to your article

Submit your next manuscript at $\boldsymbol{\nabla}$ springeropen.com 